\title{
Influence of Spindle Speed on Yarn Quality of Flax/Cotton Blend
}

\author{
Lawal A.S. ${ }^{*}$, Nkeonye P.O. ${ }^{1}$ and Anandjiwala R.D. ${ }^{2}$ \\ ${ }^{I}$ Department of Textile Science and Technology, Ahmadu Bello University, Zaria, Nigeria \\ ${ }^{2}$ Council for Scientific and Industrial Research (CSIR), Port Elizabeth, South Africa and Department of Textile Science, \\ Nelson Mandela Metropolitan University, South Africa
}

\begin{abstract}
The influence of spindle speed on yarn quality was investigated. The yarn properties such as strength, breaking extension, imperfections and hairiness were studied. The strength of 39 tex 10/90 flax/cotton blended yarn was seen to have a lower value than the 59 tex equivalent yarn as spindle speed increased. But the breaking extension decreased with the increase in spindle speed. The study also revealed that both yarn hairiness and total imperfections increased as the spindle speed increased. It was judged from the experimental findings that the yarn produced from 10/90 flax/cotton blend had higher strength and was more regular than the yarn produced from 70/30 flax/cotton blend.
\end{abstract}

Keywords: Spinning speed, yarn quality, flax, cotton, strength, extension and imperfections.

\section{INTRODUCTION}

In staple yarn manufacture, ring spinning system is still over-shadowing the spun yarn production techniques amongst all the spinning systems, mainly because of the special characteristics of these yarns which provide excellent apparel fabric properties [1,2]. Different unconventional spinning techniques such as rotor, friction and air jet systems produce yarns at a much faster rate than the ring spinning system. But these yarns are not comparable with ring yarns in terms of strenght, especially as an end product of fabric for apparels [3,4].

The productivity of ring frame is a major factor contributing to the profitability of a spinning mill and higher spindle speed has become necessary for higher productivity [5]. Problems encountered in spinning yarns at high spindle speeds include yarn breakage rate, hairiness, strength loss and fly generation $[1,6]$. Consequently, production of acceptable yarn is achieved only at relatively low speeds.

The present study aims to investigate the effects of three different ring spinning spindle speeds on the quality of flax/cotton blended yarns produced, and thereby to ascertain the optimum spindle speed level for better yarn quality.

\section{MATERIALS AND METHODOLOGY}

\section{Materials}

The raw materials include dew-retted flax straws and cotton. The retted flax straws were obtained from North West Province of South Africa, and cotton fibres were obtained from KwaZulu-Natal Province of South Africa. The extracted flax fibres were processed on Temafa machines (Lin-Opener and Lin-Star) before blending with cotton in the blendomat.

*Address correspondence to this author at the Department of Textile Science and Technology, Ahmadu Bello University, Zaria, Nigeria; Tel: +2348023737968; E-mail: abuslawal@yahoo.com

\section{Methodology}

Before blending the flax and cotton fibres, the mean fibre length of the two fibres were measured by using a Bear sorter method. The resulting length distribution diagram was used for calculating the mean fibre length, upper quartile length or effective length and short fibre percentage.

The blending of the two fibres (flax and cotton) was done on blendomat in proportions of 10/90, 30/70, 50/50 and $70 / 30$ flax/cotton. This was followed by drawing and drafting of the sliver to the required mass per unit length to obtain the roving needed for ring spinning.

A roving of $0.6 \mathrm{~K}$ tex was used to produce 39 tex and 59 tex yarns for each of the 10/90, 30/70, 50/50 and 70/30 flax/cotton blends. Spinning was carried out on a double sided Zinser 319 ring frame with 152 spindles on both sides. Variable spindle speeds of 7000, 9000 and 11000rpm respectively were used for the production of all the yarn samples. Although, it was difficult to spin fine count (39 tex) from $70 / 30$ flax/cotton blend under high spindle speeds due to unsuitable spinning conditions.

\section{Conditioning of the Samples}

All the yarn samples were conditioned for 24 hours under standard atmospheric conditions of $21 \pm 1^{\circ} \mathrm{C}$ and a relative humidity of $65 \pm 2 \%$.

\section{Testing of the Samples}

Single yarn strength (tenacity), hairiness, irregularity (U\%) and imperfections of all the samples were carried out at standard conditions [7].

The Titan Universal Strength Tester at a gauge length of $500 \mathrm{~mm}$ with a maximum load of $6000 \mathrm{cN} /$ tex was used for single yarn strength measurement. The hairiness index $\mathrm{H}$, which is the measurement unit for hairiness of approximately $1 \mathrm{~cm}$ length of yarn was obtained from the Zellweger Hairiness meter. The Zellweger Hairiness is a component attached to the Uster Evenness Tester, which scans the total 
length of all the fibres protruding from the yarn surface measured on the $1 \mathrm{~cm}$ yarn length.

Yarn unevenness and imperfections were observed on the Uster Evenness Tester UT3 at a testing speed of $400 \mathrm{~m} / \mathrm{min}$ for 1 minute, keeping thin level at $-50 \%$, thick level at $+50 \%$ and neps level at $+200 \%$ for a time period of 1 minute.

\section{RESULTS}

Table 1. Properties of Flax and Cotton Fibres

\begin{tabular}{|c|c|c|}
\hline Property & Flax & Cotton \\
\hline \hline Linear density (mtex) & 373 & 165 \\
\hline Colour & Grey & Whitish- Yellow \\
\hline Short fibre content (\%) & 6.56 & 4.1 \\
\hline Mean fibre length (mm) (upper quartile) & 57 & 22 \\
\hline Tenacity (cN/tex) & 27 & 16.9 \\
\hline Micronaire & 5.2 & 4.2 \\
\hline Extension (\%) & 10.5 & 11.9 \\
\hline
\end{tabular}

Table 2. Influence of Spindle Speed on Tenacity and Extension of Flax/Cotton Blended Ring Spun Yarns

\begin{tabular}{|c|c|c|c|c|c|c|}
\hline $\begin{array}{l}\text { Blend Ratio } \\
\text { (F/C) }\end{array}$ & $\begin{array}{c}\text { Linear Density } \\
\text { (tex) }\end{array}$ & $\begin{array}{c}\text { Spindle Speed } \\
(\text { (rpm) }\end{array}$ & $\begin{array}{l}\text { Tenacity } \\
\text { (cN/tex) }\end{array}$ & $\underset{\text { Tenacity }}{\text { CVm (\%) of }}$ & $\begin{array}{c}\text { Extension } \\
(\%)\end{array}$ & $\begin{array}{c}\text { CVm (\%) of } \\
\text { Extension }\end{array}$ \\
\hline \multirow{6}{*}{$10 / 90$} & \multirow{3}{*}{39} & 7000 & 17.90 & 7.13 & 7.64 & 5.84 \\
\hline & & 9000 & 18.14 & 8.80 & 6.84 & 8.17 \\
\hline & & 11000 & 18.46 & 8.37 & 6.66 & 6.32 \\
\hline & \multirow{3}{*}{59} & 7000 & 18.60 & 5.82 & 7.80 & 6.05 \\
\hline & & 9000 & 19.36 & 7.76 & 7.51 & 4.50 \\
\hline & & 11000 & 19.87 & 5.07 & 7.05 & 8.21 \\
\hline \multirow{6}{*}{$30 / 70$} & \multirow{3}{*}{39} & 7000 & 10.73 & 22.21 & 5.81 & 13.39 \\
\hline & & 9000 & 11.91 & 15.67 & 5.54 & 9.28 \\
\hline & & 11000 & 12.47 & 15.82 & 5.43 & 13.06 \\
\hline & \multirow{3}{*}{59} & 7000 & 11.49 & 10.65 & 6.11 & 12.28 \\
\hline & & 9000 & 12.98 & 12.20 & 6.02 & 9.10 \\
\hline & & 11000 & 13.45 & 17.76 & 5.93 & 15.39 \\
\hline \multirow{6}{*}{$50 / 50$} & \multirow{3}{*}{39} & 7000 & 10.21 & 15.22 & 4.51 & 11.67 \\
\hline & & 9000 & 10.48 & 11.58 & 3.92 & 9.81 \\
\hline & & 11000 & 10.68 & 17.06 & 3.36 & 13.67 \\
\hline & \multirow{3}{*}{59} & 7000 & 10.29 & 16.17 & 5.85 & 12.99 \\
\hline & & 9000 & 11.88 & 16.78 & 5.37 & 12.54 \\
\hline & & 11000 & 11.96 & 17.83 & 5.62 & 14.46 \\
\hline \multirow{6}{*}{$70 / 30$} & \multirow{3}{*}{39} & 7000 & 4.87 & 23.17 & 2.34 & 31.72 \\
\hline & & 9000 & 4.89 & 24.54 & 2.10 & 17.35 \\
\hline & & $11000(\mathrm{~N} / \mathrm{P})$ & $\mathrm{N} / \mathrm{P}$ & $\mathrm{N} / \mathrm{P}$ & $\mathrm{N} / \mathrm{P}$ & $\mathrm{N} / \mathrm{P}$ \\
\hline & \multirow{3}{*}{59} & 7000 & 6.53 & 25.28 & 4.91 & 22.17 \\
\hline & & 9000 & 6.73 & 20.72 & 3.16 & 18.69 \\
\hline & & 11000 & 6.28 & 21.04 & 3.21 & 19.18 \\
\hline
\end{tabular}




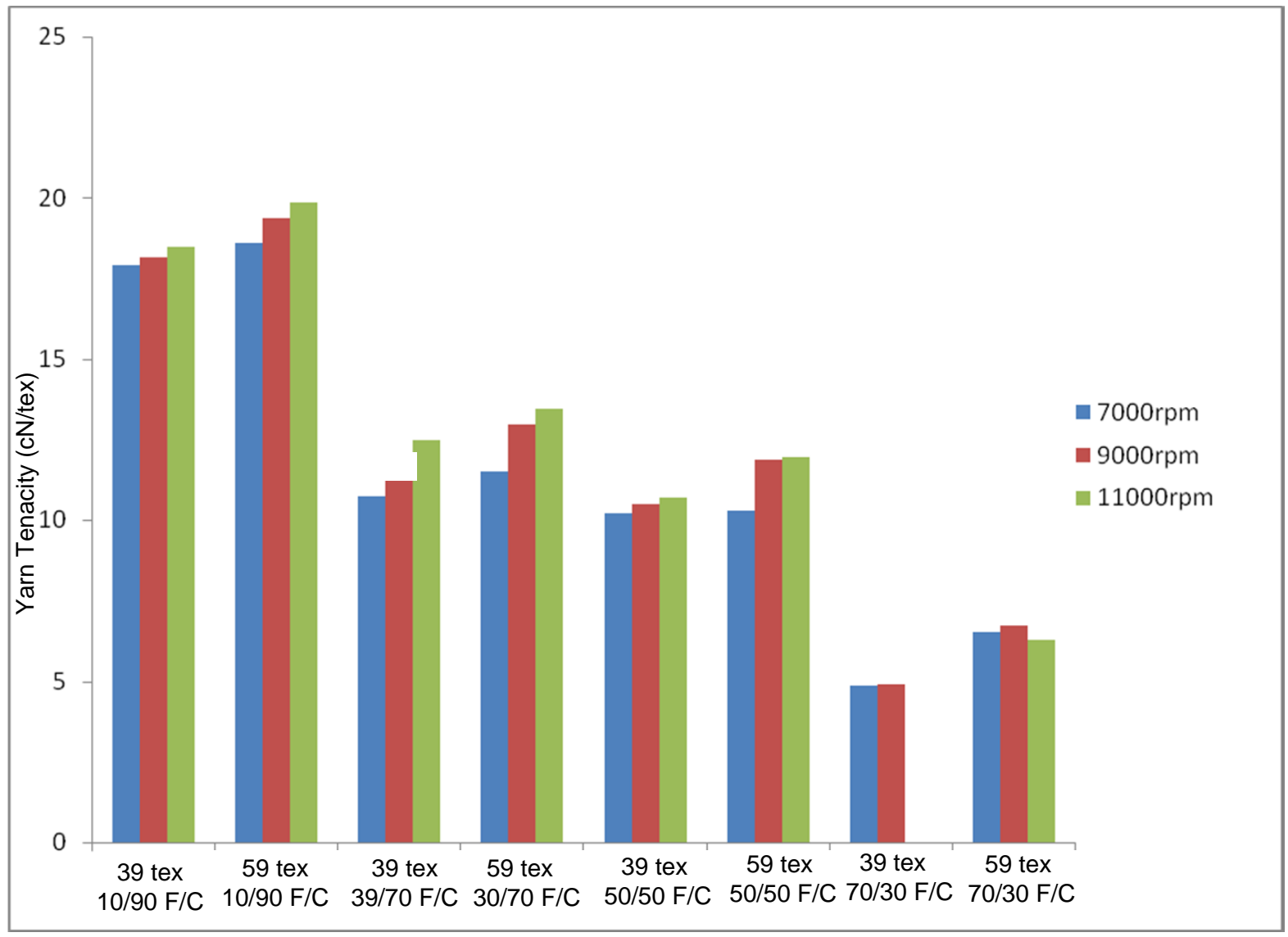

Fig. (1). Influence of spindle speed on yarn tenacity.

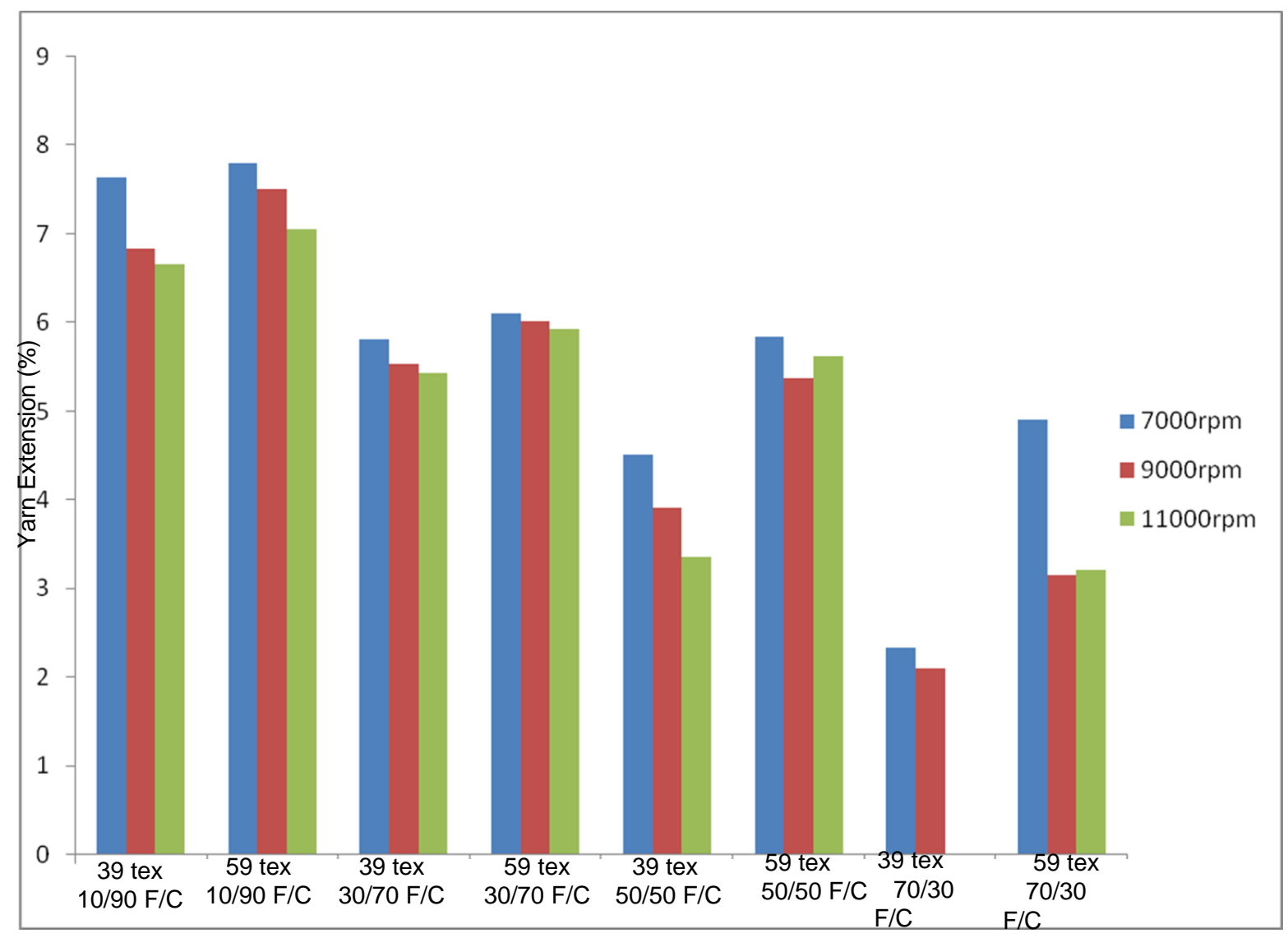

Fig. (2). Influence of spindle speed on yarn extension. 
Table 3. Influence of Spindle Speed on Evenness and Imperfections of Flax/Cotton Blended Ring Spun Yarns

\begin{tabular}{|c|c|c|c|c|c|c|c|c|c|}
\hline \multirow[b]{2}{*}{$\begin{array}{l}\text { Blend } \\
\text { Ratio } \\
(\mathrm{F} / \mathrm{C})\end{array}$} & \multirow[b]{2}{*}{$\begin{array}{l}\text { Linear } \\
\text { Density } \\
\text { (tex) }\end{array}$} & \multirow[b]{2}{*}{$\begin{array}{l}\text { Spindle Speed } \\
\text { (rpm) }\end{array}$} & \multirow[b]{2}{*}{$\begin{array}{l}\text { Um } \\
(\%)\end{array}$} & \multirow[b]{2}{*}{$\begin{array}{l}\text { CVm } \\
(\%) \text { of } \\
\text { Um }\end{array}$} & \multicolumn{3}{|c|}{ Imperfection Per Km } & \multirow[b]{2}{*}{$\begin{array}{c}\text { Total Imperfections } \\
\text { Per Km }\end{array}$} & \multirow[b]{2}{*}{$\begin{array}{l}\text { Hairiness } \\
\text { (H) }\end{array}$} \\
\hline & & & & & $\begin{array}{c}\text { Thin } \\
\text { Places } \\
\text { (-50) Per } \\
\text { Km }\end{array}$ & $\begin{array}{c}\text { Thick Places } \\
(+50 \%) \text { Per } \\
\text { Km }\end{array}$ & $\begin{array}{c}\text { Neps } \\
(+200 \%) \text { Per } \\
\text { Km) }\end{array}$ & & \\
\hline \multirow{6}{*}{$10 / 90$} & & 7000 & 12.24 & 15.56 & 11 & 237 & 176 & 424 & 6.26 \\
\hline & 39 & 9000 & 12.40 & 15.80 & 10 & 281 & 189 & 480 & 6.68 \\
\hline & & 11000 & 12.53 & 15.91 & 15 & 274 & 204 & 493 & 6.95 \\
\hline & & 7000 & 10.44 & 13.60 & 1 & 58 & 45 & 104 & 7.22 \\
\hline & 59 & 9000 & 10.84 & 13.80 & 0 & 52 & 60 & 112 & 7.54 \\
\hline & & 11000 & 10.90 & 13.87 & 7 & 62 & 49 & 118 & 7.81 \\
\hline \multirow{6}{*}{$30 / 70$} & & 7000 & 20.43 & 26.07 & 1351 & 2361 & 2001 & 5713 & 8.44 \\
\hline & 39 & 9000 & 20.92 & 26.72 & 1731 & 2669 & 3226 & 7626 & 8.84 \\
\hline & & 11000 & 21.10 & 26.84 & 1792 & 2756 & 3421 & 7969 & 9.56 \\
\hline & & 7000 & 17.11 & 23.13 & 636 & 1439 & 1429 & 3504 & 8.60 \\
\hline & 59 & 9000 & 17.98 & 23.01 & 807 & 1341 & 1410 & 3558 & 8.88 \\
\hline & & 11000 & 18.65 & 23.87 & 802 & 1501 & 1595 & 3898 & 9.08 \\
\hline \multirow{6}{*}{$50 / 50$} & & 7000 & 27.37 & 34.46 & 6254 & 4640 & 8119 & 19013 & 8.17 \\
\hline & 39 & 9000 & 28.22 & 35.74 & 6790 & 4828 & 8196 & 19814 & 8.41 \\
\hline & & 11000 & 29.28 & 33.91 & 6817 & 4824 & 8671 & 20312 & 8.20 \\
\hline & & 7000 & 23.77 & 30.13 & 2988 & 2978 & 4269 & 10235 & 9.12 \\
\hline & 59 & 9000 & 24.54 & 29.66 & 3146 & 3068 & 5122 & 11336 & 9.55 \\
\hline & & 11000 & 24.97 & 31.22 & 3462 & 3084 & 4979 & 11525 & 9.20 \\
\hline \multirow{6}{*}{$70 / 30$} & & 7000 & 38.51 & 44.65 & 11012 & 5184 & 8728 & 24924 & 9.06 \\
\hline & 39 & 9000 & 40.10 & 46.32 & 10105 & 6248 & 10327 & 26680 & 13.01 \\
\hline & & $11000(\mathrm{~N} / \mathrm{P})$ & $\mathrm{N} / \mathrm{P}$ & $\mathrm{N} / \mathrm{P}$ & $\mathrm{N} / \mathrm{P}$ & $\mathrm{N} / \mathrm{P}$ & $\mathrm{N} / \mathrm{P}$ & $\mathrm{N} / \mathrm{P}$ & $\mathrm{N} / \mathrm{P}$ \\
\hline & & 7000 & 35.69 & 41.05 & 8529 & 4542 & 9263 & 22334 & 10.14 \\
\hline & 59 & 9000 & 36.63 & 40.21 & 9314 & 5621 & 9475 & 24410 & 12.98 \\
\hline & & 11000 & 36.81 & 41.39 & 9001 & 6548 & 9517 & 25066 & 11.16 \\
\hline
\end{tabular}

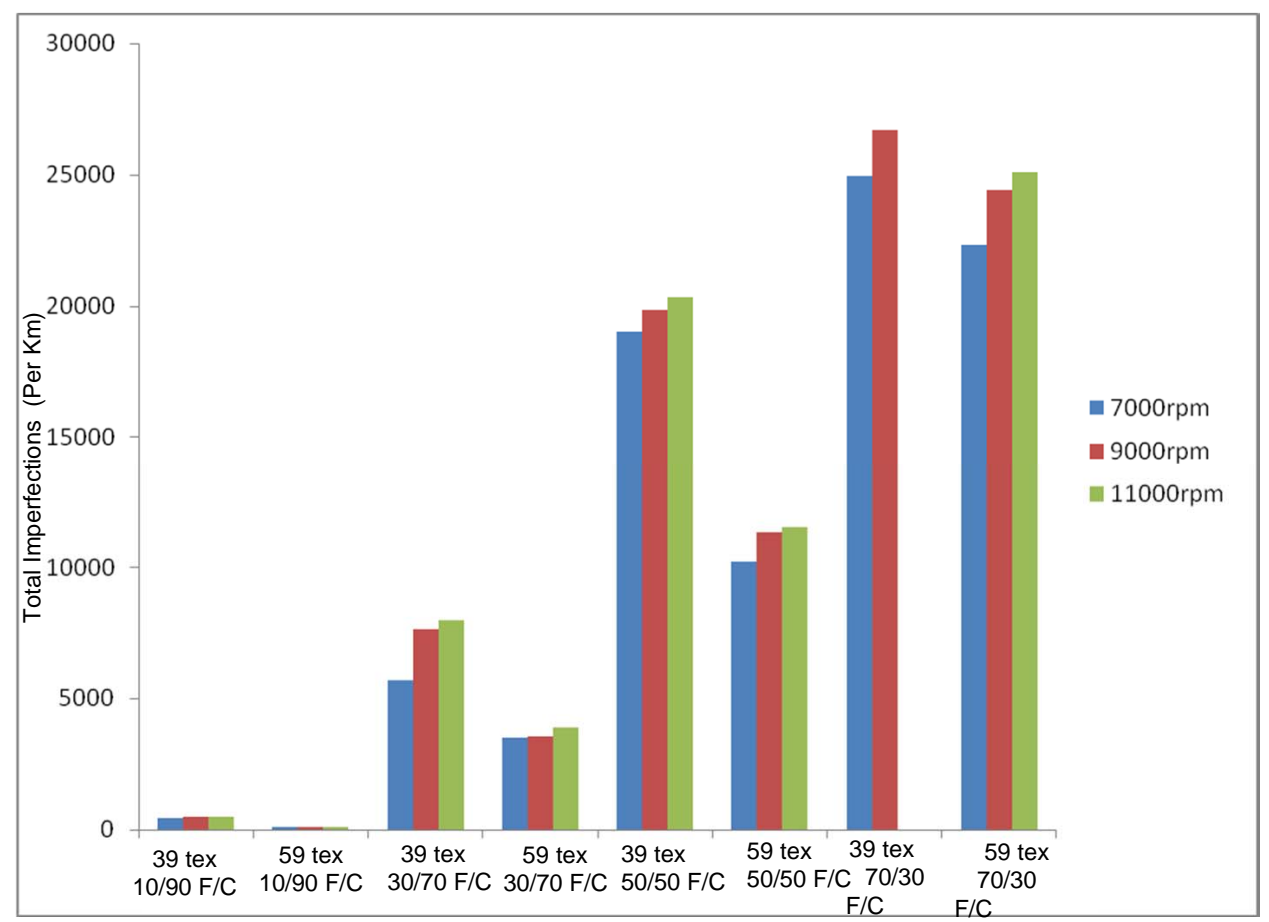

Fig. (3). Influence of spindle speed on yarn imperfections. 


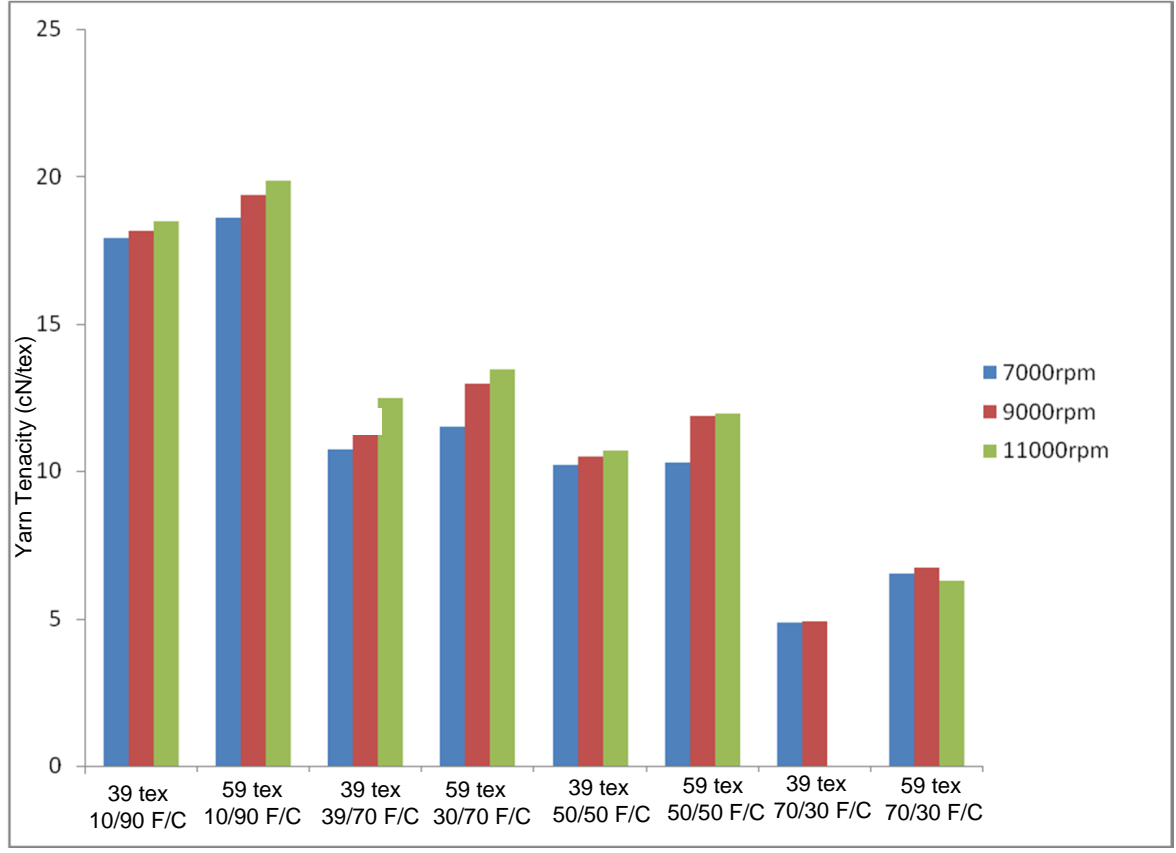

Fig. (4). Influence of spindle speed on yarn hairiness.

\section{DISCUSSION}

Table 1 shows the properties of flax and cotton fibres measured. It can be seen from Table $\mathbf{1}$ that flax is coarser than cotton. Also, Table 1 indicates that flax has higher tenacity than cotton, but the \% extension of cotton is higher than that of flax. The migration behaviour of a fibre is influenced by its mean radial position in yarn. The flax fibres been the surface fibres show least tendency to migrate, while cotton fibres been the core fibres exhibit short term but low amplitude migration $[8,9]$.

As observed from Table 2 and Fig. (1) as the spindle speed increases, the tenacity of flax/cotton blended yarns produced also increases. This is attributed to the fact that, as the spindle speed increases during spinning, the frictional force also increases, and this force tends to straighten the fibres in the drafting field [1]. At high drafting speed, there is an increase in tenacity, but, as the spindle speed continues to increase due to high drafting force, there will be uncontrolled movement of the fibres in the drafting field and the dragging of the fibres from the front roller nip will lead to deterioration in tenacity. Again, as the spindle speed increases, due to high tension, the yarn breakage rate increases and the machine efficiency gets affected [1,2]. Therefore, the optimum spindle speed depends on the mechanical condition of the machine and the nature of the raw material.

The breaking extension of flax/cotton blended yarns decreases as the spindle speed increases as shown in Table $\mathbf{2}$ and Fig. (2). Also, as the percentage of flax content in the blend increases, the breaking extension decreases. The breaking extension of 59 tex ring spun yarn is higher than that of 39 tex ring spun yarn under the same spinning conditions, due to differences in their tenacity, the former being higher than the latter.

It can be observed in Tables $\mathbf{2}$ and $\mathbf{3}$, also in Figs. (1-4) that it was not possible to spin 39tex 70/30 flax/cotton blended ring spun yarn at a spindle speed of $11000 \mathrm{rpm}$ and this was attributed to high tension and frequent yarn breakages arising from decreasing strength of the yarn.

As shown in Table 3 and Fig. (3), increase in spindle speed causes an increase in total imperfections (neps, thin and thick places) of flax/cotton blended yarns. As the spindle speed increases, the ratio of static to dynamic friction increases, which tends to improve the imperfections. Again, increase in drafting speed increases the average fibre tension, which results in an increase in the dragging out or pulling force exerted by the fast moving fibres. Also, at high drafting speed, there is roller vibration and the front roller nip does not remain stable, which may lead to uneven yarn [1-3]. The drafting wave is formed as a result of non-steady motion of the fibres in the drafting field. Due to the fact that the flax and cotton fibres are not of the same height, the shorter fibres (flax) are released by the back rollers before their front ends have reached the front rollers. These fibres (flax) tend to come out of the front rollers in clots and so cause alternate thick and thin places in the drafted material. At high spindle speed, more fly is deposited on the yarn due to high air current. Moreover, the higher breakage rate and irregularity associated with the high spindle speed also contributed to the occurrence of yarn faults.

It was observed from Table 3 and Fig. (4) that as the spindle speed increases, the hairiness of flax/cotton blended yarns also increases. This is due to the fact that at higher spindle speed, the number of floating fibres increases and the fibres tend to protrude from the body of the yarn thereby contributing to the yarn hairiness.

\section{CONCLUSION}

The tenacity and total imperfections (neps, thin and thick places) of flax/cotton blended yarns increased, whereas, the breaking extension decreased with the increase in spindle speed for all the yarn linear densities and blend proportions 
studied. But, the tenacity value decreased, while the total imperfections increased, as the percentage of the flax content in the flax/cotton blends increased. It was not possible to increase the spindle speed beyond $9000 \mathrm{rpm}$ for 39 tex 70/30 flax/cotton blended yarn due to frequent yarn breakages. It is possible to process 50/50 flax/cotton blends at higher spindle speeds for both fine and coarse count ring spun yarns. Thus, the 10/90 flax/cotton blended yarn produced gave the best quality in terms of strength and uniformity of the yarn.

A major disadvantage with the dew-retted flax utilized in this study is the high amount of short fibres in the flax which contributed to the decrease in the quality of the blended yarns produced as the percentage of flax in the blend increased. Hence, a more uniform fibre length would lead to better yarn quality. The uniformity in fibre length can be achieved with improvements in retting systems and processing equipment.

\section{ACKNOWLEDGEMENTS}

The authors would like to thank the staff and management of Council for Scientific and Industrial Research (CSIR), Port Elizabeth, South Africa, for their contribution during the conduct of this research. The funding support from Carnegie Corporation, New York Projects, in Ahmadu Bello University, Zaria, Nigeria is sincerely acknowledged.

\section{REFERENCES}

[1] T. Nemailal, "Effect of speed, twist, draft on ring spun yarn," Indian Textile J., vol. 11, pp. 19-28, 2002.

[2] P.R. Lord, Handbook of Production, Technology, Science and Economics. The Textile Institute: Woodhead Publishing Ltd., 2003, p. 71 .

[3] B. Azzouz, M.B. Hassan, and F. Sakli, "Quality prediction and optimizing cotton blend using ANN," Indian Textile J., vol. 1, pp. 27-34, 2007.

[4] A.S. Lawal, Studies on the Effects of Some Spinning Parameters on Various Blends of Flax/Cotton Yarns Spun Using Ring and Rotor Spinning Techniques. Ph.D Thesis. Ahmadu Bello University, Zaria, Nigeria, 2008

[5] P. Grosberg, and C. Iype, Yarn Production, Theoretical Aspects, The Textile Institute: Manchester, UK, 1999, pp. 99-113.

[6] Schlafhorst, Preparation of Linen Fibres and Their Processing in Ring and Rotor Spinning, Manchenglabatch, Germany, 1995, pp. 33.

[7] British Standards Handbook No.11. Methods of Tests for Textile. British Standards Institution: London, 1963, no. 105, 2863, pp. 10, 222.

[8] J. Ramakrishnan, "Migration behaviour of fibres in short staple spun yarns," Textile Asia, vol. 4, pp. 24-28, 2007.

[9] M. B. Hassan, "Effect of fibre initial modulus on its migratory behaviour in yarns," Textile Res. J., vol. 41, no. 9, pp. 812-820, 1971. 